\begin{tabular}{|l|l|l||}
\hline \multicolumn{2}{|c|}{ PublisherInfo } \\
\hline \hline PublisherName & $:$ & BioMed Central \\
\hline \hline PublisherLocation & $:$ & London \\
\hline \hline PublisherImprintName & $:$ & BioMed Central \\
\hline \hline
\end{tabular}

\title{
Citrate anticoagulation for hemofiltration
}

\begin{tabular}{|l|l|l||}
\hline \multicolumn{2}{|c||}{ ArticleInfo } \\
\hline \hline ArticleID & $:$ & 4111 \\
\hline \hline ArticleDOI & $:$ & $10.1186 /$ ccf-1999-333 \\
\hline \hline ArticleCitationID & $:$ & 333 \\
\hline \hline ArticleSequenceNumber & $:$ & 48 \\
\hline \hline ArticleCategory & $:$ & Paper Report \\
\hline \hline ArticleFirstPage & $:$ & 1 \\
\hline \hline ArticleLastPage & $:$ & 4 \\
\hline \hline & & RegistrationDate : 1999-5-18 \\
\hline ArticleHistory & $:$ & OnlineDate \\
\hline \hline ArticleCopyright & $:$ & Current Science Ltd1999-5-18 \\
\hline \hline ArticleGrants & $:$ & \\
\hline \hline ArticleContext & $:$ & 130541111 \\
\hline \hline
\end{tabular}




\section{Keywords}

Anticoagulation, blood flow, clotting, continuous renal replacement therapy, heparinization

\section{Comments}

A retrospective, observational, uncontrolled study in a small group of patients has severe limitations. However, this paper offers an apparently safe and simple method of providing CVVH in those patients in whom heparin needs to be avoided. Whether this method offers any advantages over heparin or other methods of circuit anticoagulation requires further investigation.

\section{Introduction}

Continuous renal replacement therapies (CRRTs) have gained favor over intermittent hemodialysis (IHD) in critically ill patients over recent years. This is primarly due to the hemodynamic instability associated with IHD. Regardless of mode employed, all CRRTs require circuit anticoagulation. Heparin is the commonest agent employed but is known to cause hemorrhagic complications and can induce thrombocytopenia. A variety of alternative agents have been trialed, but to date none has overcome these problems without inducing other difficulties. Trisodium citrate is one such alternative, whose use in CRRT was first described in 1961. It achieves anticoagulation in the circuit by chelation of ionized calcium, which reverses when re-entering the body where citrate is rapidly metabolised to bicarbonate (predominately in the liver). However, its administration was cumbersome and resulted in metabolic complications. The authors devised a novel technique of employing regional citrate anticoagulation in a continuous venovenous hemofiltration $(\mathrm{CVVH})$ circuit and retrospectively analysed the first 17 patients in whom it was tried.

\section{Aims}

To assess the ease, effectiveness and safety of regional citrate anticoagulation in a CVVH circuit. 


\section{Methods}

Retrospective analysis of patient records was undertaken to establish demographic factors, case history including renal replacement, contraindication to heparin, complications and outcome.The CVVH circuit was set up conventionally. Trisodium citrate was included in the replacement fluid - a hypotonic sodium chloride $(100 \mathrm{mmol})$ solution containing magnesium chloride and dextrose. This mixes with the patient's blood prior to the filter. After the filter, a calcium gluconate or chloride infusion is added, prior to return to the patient, the rate determined by a sliding scale, based on blood ionized calcium.

\section{Results}

The 17 patients were a heterogeneous group, representative of a typical general/cardiac intensive care unit (ICU) population. All were in multi-organ failure and had contraindications to heparin. Average filter life was $29.5 \pm 17.9 \mathrm{~h}$. Effective renal replacement therapy was achieved in all cases. There was no measurable effect on clotting nor any hemorrhagic complications. Two patients developed citrate toxicity but without clinical sequelae. No patients developed hypernatremia or metabolic acidosis. Nine of the 17 patients survived.

\section{Discussion}

This method of circuit anticoagulation achieved comparable filter life to heparin anticoagulation. It was far simpler to administer and resulted in no significant metabolic derangements as compared to previous designs of citrate anticoagulation which were cumbersome and toxic. Efficacy of renal replacement was excellent and comparible to other methods. The two patients who showed biochemical citrate toxicity (low ionized calcium and worsening metabolic acidosis) both had lactic acidosis secondary to hepatic failure, which is a relative contraindication to this method. The overall mortality was comparable to reported series of patients with multi-organ failure. However, if you compare the APACHE II scores of these patients to similar groups, this group had higher scores but the same mortality suggesting that there may be some additional survival benefit conferred by this therapy. To prove this would require a prospective trial in a larger group. The only drawback to the method is the cost of producing the citrate containing solution. This could be overcome if sufficient demand were generated such that commercial manufacture became viable. The authors conclude that 'Regional citrate anticoagulation by our method is practical, safe and efficacious in patients in whom heparin is relatively or absolutely contraindicated'. 


\section{References}

1. Palsson R, Niles JL: Regional citrate anticoagulation in continuous venovenous hemofiltration in critically ill patients with a high risk of bleeding. Kidney Int. 1999, 55: 1991-1997.

This PDF file was created after publication. 